\title{
Assessment of knowledge about Essential Obstetric Care among Pregnant Females of Punjab, Pakistan
}

\author{
SAMINA WASEEM ${ }^{1}$, AESHA SADAF RIZWAN², NASER FAIZ UDDIN³ , QAMAR ZAMAN ${ }^{4}$, TAHIR MUKHTAR SAYED ${ }^{5}$, \\ SAQIB ALI ${ }^{6}$ \\ ${ }^{1}$ Assistant Professor Community Medicine, Sheikh Zayed Medical College, Rahim Yar Khan \\ ${ }^{2}$ Assistant Professor, Gynaecology and Obstetrics, Shahida Islam Medical College, Lodhran \\ ${ }^{3}$ Medical Practitioner, Abu Dhabi Health Services Company (Seha) Abu Dhabi- UAE \\ ${ }^{4}$ Clinical Instructor College of Medicine /General Physician, Internal Medicine/ Otorhinolaryngology ENT, Mohammed Bin Rashid University \\ of Medicine and Health Sciences) Dubai (U.A.E \\ ${ }^{5}$ Associate Professor of Medicine, Fauji Foundation Medical College, Rawalpindi \\ ${ }^{6}$ Assistant Professor, Data Analyst Department of Computer Science, University of Agriculture, Faisalabad \\ Corresponding Author: Dr. Samina Waseem, Email: drsaminaryk@gmail.com, Cell No.+923008674319
}

\begin{abstract}
Purpose: The first step towards achieving the goals of the Child Health and Reproductive Health Program is to raise awareness and educate pregnant women about the essential features of basic and emergency maternity and neonatal care.

Aims: To assess the level of knowledge on essential antenatal care among pregnant females.

Study Design: A cross-sectional study.

Place and Duration: The study was conducted at Gynaecology and Obstetrics department of Sheikh Zayed Hospital, Rahim Yar Khan and Shahida Islam Teaching Hospital, Lodhran for the duration of six months from $16^{\text {th }}$ August 2020 to $15^{\text {th }}$ February 2021.

Methods: This study was held among 110 pregnant women who arrived based on information on antenatal care in the literature. Participants were selected by simple random sampling, and data on "essential obstetrics care" information was collected through a structured interview program based on the mother-Child Protection Charter.

Results: This study shows that $46.4 \%$ of participants have sufficient knowledge of the signs / symptoms of the dangers of pregnancy, $44.5 \%$ have sufficient knowledge of antenatal care and only $9.1 \%$ have sufficient knowledge of maternity care. It was found that knowledge of obstetric care is significantly related to the education level of pregnant women.

Conclusions: The knowledge gap found in this study indicates the need to reassess the effectiveness of health education activities implemented through the health system and improve / renew the content and quality of health education materials in order to raise awareness among pregnant women.
\end{abstract}

Keywords: Antenatal care, MCP card, Obstetrics care, Primary health care.

\section{INTRODUCTION}

The health of a country is directly proportional to the health of women, especially those of childbearing age ${ }^{1}$. Therefore, much attention has been paid to the health of mothers and babies $(\mathrm{MCH})$ around the world, and Pakistan is no exception. Maternal and child health care, including family planning services, is one of the eight components of primary care provided in Pakistan. Reproductive and Child Health programs were launched in 1997-98 which was the primary obstetrics care ${ }^{2-3}$. It includes Basic obstetrics care for all pregnant women; 1 . Registration of early pregnancy, 2. Provision of at least three antenatal tests by ANM / Doctor, 3. Provision of safe home or facility birth 4 .

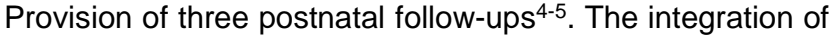
antenatal care programs has contributed to the widening of the scope of their services, and this has contributed to a significant reduction in maternal and infant mortality in the country ${ }^{6}$. As part of the effective implementation of elements of antenatal services, a common card "Mother and Child Protection" (MCP) was developed as a tool with a graphic presentation of demographic characteristics, information about the mother and the child which encompassed Antenatal, antenatal and postpartum hemorrhage, maintenance details and practices $^{7-8}$. The MCP helps families learn, understand, and apply practices to achieve good health in pregnant women, young mothers, and children. The card also serves as a powerful tool for monitoring and providing preventive and curative maternal and child health services ${ }^{9-10}$. The MCP is used nationwide and is easy to understand by both mothers and healthcare professionals, thanks to the visual recording of mother and baby details. Appropriate obstetric knowledge of antenatal women will be reflected in their knowledge and understanding of the information obtained from the MCP card $^{11}$. On this basis, a study was planned and carried out to assess the level of knowledge of pregnant women about "basic obstetric care".

\section{METHODS}

It is a descriptive, cross-sectional population study conducted to assess the level of knowledge about the 'basic obstetric care' of pregnant females. The sample size was calculated using the formula [4 PQ / L2] which came to be 91.9 , at $95 \%$ level with $20 \%$ limit of accuracy. The final sample size was calculated taking into account $10 \%$ nonresponse and rounded to 110 pregnant women. The list of antenatal women was obtained from the records, and 110 pregnant women were selected by simple randomization.

Data collection was done through home-to-home visits using a structured questionnaire containing background information and knowledge of basic maternity care developed for the MCP card. Basic knowledge of 
obstetric care was assessed in three elements: 1. Knowledge of Antenatal care, 2. Signs of risks in pregnancy, 3. Obstetric care. For each of the items, the correct answer to the question was scored "1", and the remaining answers were scored "0". The maximum score that can be obtained at the end of the interview is "9" and a score above $50 \%$ is considered sufficient information. Data were analyzed using SPSS version 17 . The student's t-test was used to assess statistical significance between the mean scores and antenatal care information. The study was conducted after obtaining the approval of the Ethical Committee. Informed consent was obtained prior to data collection.

\section{RESULTS}

Information on antenatal care is provided in Table 1. It was observed that $66.3 \%$ of participants had correct information on the timing of antenatal registration, but $60 \%$ did not know the required minimum antenatal checks. In addition, $56.3 \%$ of the women knew that blood pressure should be measured at each visit, while $32.7 \%$ of the participants were unaware of the minimum number of iron and folic acid tablets to take during pregnancy. The knowledge of the correct dose of anti-tetanus injection was good [80.9\%], but the knowledge of emergency preparations was insufficient as $59.1 \%$ of the participants were unaware of this.

Table 1: Information concerning antenatal care.

\begin{tabular}{|l|l|l|}
\hline Frequency & $\begin{array}{l}\text { Characteristic } \\
{[n=110]}\end{array}$ & Percentage \\
\hline Timing of antenatal registration & 73 & 66.3 \\
\hline Correct (1st trimester) & 23 & 22.7 \\
\hline Wrong & 12 & 10.9 \\
\hline Do not know & 41 & 37.2 \\
\hline Minimum number of antenatal check ups & 60 \\
\hline Correct (4 times) & 66 & 2.7 \\
\hline Wrong & 3 & 56.3 \\
\hline Do not know & 6 & 38.1 \\
\hline Number of times BP should be measured during pregnancy \\
\hline Correct (during every visit) & 62 & 5.4 \\
\hline Wrong & 42 & 44.5 \\
\hline Do not know & 6 & 32.7 \\
\hline Minimum number of IFA tablets to be taken during prenancy \\
\hline Correct (100 tablets) & 49 & 22.7 \\
\hline Wrong & 36 & 80.9 \\
\hline Do not know & 25 & 11.8 \\
\hline Number of TT injections to be given during pregnancy \\
\hline Correct (2 injections) & 89 & 7.2 \\
\hline Wrong & 13 & 59.1 \\
\hline Do not know & 8 & 29.1 \\
\hline Preparation for emergency labour* & 46.3 \\
\hline Do not know & 65 & 32 \\
\hline Save money & 51 & \\
\hline Arrange for transport & \multicolumn{2}{|l|}{} \\
\hline
\end{tabular}

Table 2 provides information on the signs and symptoms of the risk of pregnancy. It was observed that $45 \%$ of the participants responded to abdominal pain as an important sign of danger of pregnancy, followed by $34.5 \%$ of vaginal bleeding. No pallor case was reported.

About $26.4 \%$ were unaware of any dangerous signs of pregnancy. Information on maternity care is provided in
Table 3. This study shows that $71.8 \%$ of respondents were not aware of the "five cleans standards" of home / institutional birth and $83.6 \%$ were unaware of the importance of the family planning symbol, the Red Inverted Triangle.

Table 2: Information regarding danger signs and symptoms of

\begin{tabular}{|c|c|c|}
\hline Characteristic & $\begin{array}{l}\text { Frequenc } \\
y[n=110]\end{array}$ & Percentage \\
\hline Do not know & 29 & 26.4 \\
\hline Bleeding per vagina & 38 & 34.5 \\
\hline Fever & 11 & 10 \\
\hline Pedal Oedema & 16 & 14.5 \\
\hline Convulsions/Unconsciousness & 27 & 24.5 \\
\hline Pain Abdomen & 58 & 52.7 \\
\hline $\begin{array}{l}\text { Bursting of bag (Rupture of } \\
\text { membrane) }\end{array}$ & 9 & 8.2 \\
\hline
\end{tabular}

Table 3: Information regarding obstetric care.

\begin{tabular}{|l|l|l|}
\hline Characteristic & $\begin{array}{l}\text { Frequency } \\
{[\mathbf{n}=110]}\end{array}$ & Percentage \\
\hline Five Cleans of home / institution delivery \\
\hline Do not Know & 79 & 71.8 \\
\hline Clean Hands & 12 & 11 \\
\hline Clean Surface & 16 & 14.5 \\
\hline Clean Blade & 11 & 10 \\
\hline Clean Umbilical & 23 & 20.9 \\
\hline Cord/Cord tie & \multicolumn{1}{|l|}{} \\
\hline Clean Clothes & 2 & 1.8 \\
\hline $\begin{array}{l}\text { Meaning of family planning symbol [inverted red triangle] } \\
\text { when shown }\end{array}$ & 18 & 16.4 \\
\hline Knows & 92 & 83.6 \\
\hline Do not know
\end{tabular}

The relationship between average outcomes and basic characteristics such as education level, family type and reading ability is shown in Table 4.

Table 4: Relationship amid knowledge scores and background features.

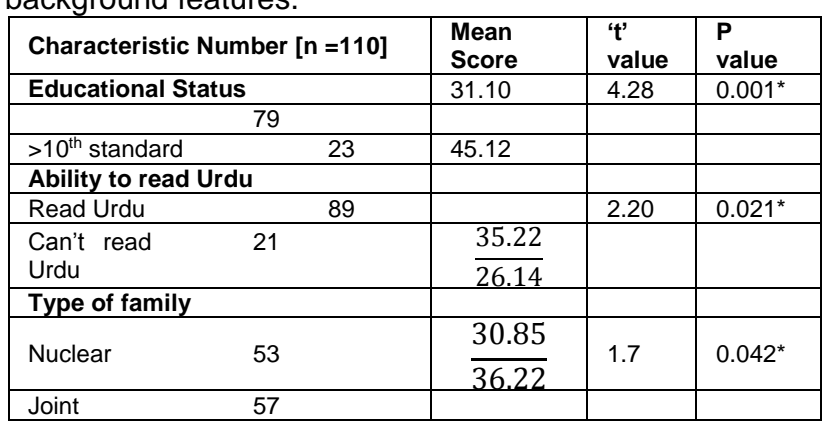

This study shows that $46.4 \%$ of participants have sufficient knowledge of the signs / symptoms of the dangers of pregnancy, $44.5 \%$ have sufficient knowledge of antenatal care and only $9.1 \%$ have sufficient knowledge of maternity care.

\section{DISCUSSION}

Adequate knowledge of antenatal and maternity care for pregnant women is a preliminary step to achieving the goals of the antenatal program. While the mean age of the 
study participants was $25.10 \mathrm{~W}$ years, the J. Laishram study found that the mean age of the participants was 29.5 . About $58 \%$ were high school graduates and $89 \%$ could read and write Urdu. In this study, $46.4 \%$ of participants had sufficient knowledge of antenatal care, while the Manju Sharma study shows that $51.2 \%$ of participants had sufficient knowledge $\mathrm{e}^{10-11}$. While approximately $44.5 \%$ of participants knew the number of iron and folic acid tablets to take during pregnancy, $80.9 \%$ correctly answered the number of tetanus toxoid injections to be administered. J. Laishram showed that $34.2 \%$ of participants knew the correct number of iron and folic acid tablets, similar to the results of this study ${ }^{12}$. Approximately $59.1 \%$ of the respondents indicated that they are not aware or have no prior plans or preparations for an emergency work situation. About $66.3 \%$ of the respondents knew the time of antenatal registration, but only $37.2 \%$ knew the minimum number of antenatal visits. A maternal healthcare utilization study in the Kancheepuram region found that $96.6 \%$ of antenatal mothers had the required minimum antenatal visits, and about $99 \%$ of births were in an institution ${ }^{13-14}$. More than $90 \%$ have been vaccinated with tetanus toxoid while consuming 100 or more IFA tablets. In this study, $52.7 \%$ of participants said abdominal pain was a dangerous sign of pregnancy, and $34.5 \%$ said it was vaginal bleeding as danger sign. Kapil Gyawali reported that $42.2 \%$ of participants felt abdominal pain as an important sign of the danger of the upcoming delivery ${ }^{15-16}$. Overall, $46.4 \%$ had adequate knowledge of the dangers of pregnancy signs and symptoms. Only $9.1 \%$ of the participants in this study had sufficient knowledge of the proper elements of maternity care. Almost $71.8 \%$ of pregnant women are unaware of the importance of " five clean elements" being given at home or in an institution for the prevention of neonatal infections, which is a cause for concern. Studies from Nepal, Pakistan and Nigeria have found that infections are responsible for up to $40 \%$ of newborn deaths, mainly due to insufficient knowledge of clean birth practices ${ }^{17-18}$. The analysis of the relationship between the level of knowledge and the characteristics of the predecessors showed that the mother's education played an important role in her knowledge about antenatal care. People from united families obtained better results than nuclear families. The Laishram and Manna studies also showed similar statistically significant results. This study showed that there is a significant relationship between education level and family type in terms of improving the target group's knowledge of antenatal care ${ }^{17-}$ 18. However, this study shows that there is a large gap between the literacy rate and the level of knowledge about antenatal / delivery care. The study of Tara M.S. revealed that only less than $70 \%$ of health professionals are knowledgeable to provide health education to antenatal mothers. According to a recent article, antenatal care in Pakistan is around $50 \%$ for multiple visits and around $10 \%$ for more than four visits, while the availability of trained personnel at delivery is only around $20 \%{ }^{19-20}$. This strongly indicates that the coverage of antenatal care in Pakistan needs to be significantly increased. While antenatal services show better health rates thanks to a betterestablished health system, the target population's level of knowledge of the services provided needs to be improved in order to better use the services provided ${ }^{21-22}$.

\section{CONCLUSION}

The study provided sufficient information on gaps in the education of target groups based on antenatal care programs. The conducted research shows that the content and quality of health education materials related to health services for mothers and children, especially with basic maternity care and provided with MCP cards, do not reach the target group sufficiently. As mothers' level of education plays a key role in understanding and developing their knowledge, it is imperative that all would-be mothers have better educational opportunities to achieve an acceptable level of education that helps fill the knowledge gap. This would significantly contribute to reducing maternal and infant morbidity and mortality in the country.

\section{REFERENCES}

1. Woldeamanuel GG, Lemma G, Zegeye B. Knowledge of obstetric danger signs and its associated factors among pregnant women in Angolela Tera District, Northern Ethiopia. BMC research notes. $2019 \mathrm{Dec} ; 12(1): 1-6$.

2. Oguntunde O, Nyenwa J, Yusuf FM, Dauda DS, Salihu A, Sinai I. Factors associated with knowledge of obstetric danger signs and perceptions of the need for obstetric care among married men in northern Nigeria: a cross-sectional survey. BMC pregnancy and childbirth. 2019 Dec;19(1):1-7.

3. Haleema M, Pracheth Raghuveer RK, Mohammed IM, Mohammed IS, Mohammed M. Assessment of knowledge of obstetric danger signs among pregnant women attending a teaching hospital. Journal of family medicine and primary care. 2019 Apr;8(4):1422.

4. Geleto A, Chojenta C, Musa A, Loxton D. WOMEN's Knowledge of Obstetric Danger signs in Ethiopia (WOMEN's KODE): a systematic review and meta-analysis. Systematic reviews. 2019 Dec;8(1):1-4.

5. ljang YP, Cumber SN, Nkfusai CN, Venyuy MA, Bede F, Tebeu PM. Awareness and practice of birth preparedness and complication readiness among pregnant women in the Bamenda Health District, Cameroon. BMC pregnancy and childbirth. 2019 Dec;19(1):1-8.

6. Okonofua F, Ntoimo LF, Ogu R, Galadanci H, Gana M, Adetoye D, Abe E, Okike O, Agholor K, Abdus-Salam RA, Randawa A. Assessing the knowledge and skills on emergency obstetric care among health providers: Implications for health systems strengthening in Nigeria. PLoS One. 2019 Apr 8;14(4):e0213719.

7. Ko JY, Tong VT, Haight SC, Terplan M, Snead C, Schulkin J. Obstetrician-gynecologists' practice patterns related to opioid use during pregnancy and postpartum-United States, 2017. Journal of Perinatology. 2020 Mar;40(3):41221.

8. Lee RW, Loy SL, Yang L, Chan JK, Tan LK. Attitudes and precaution practices towards COVID-19 among pregnant women in Singapore: a cross-sectional survey. BMC pregnancy and childbirth. $2020 \mathrm{Dec} ; 20(1): 1-0$.

9. Wulandari RD, Laksono AD. Determinants of knowledge of pregnancy danger signs in Indonesia. PLoS One. 2020 May 20;15(5):e0232550.

10. Rabiee M, Jouhari Z, Pirasteh A. Knowledge of prenatal screening, down syndrome, amniocentesis, and related factors among iranian pregnant women: A cross-sectional study. International journal of community based nursing and midwifery. 2019 Apr;7(2):150.

11. Rodríguez-Blanco N, Tuells J. Knowledge and attitudes about the flu vaccine among pregnant women in the 
valencian community (Spain). Medicina. 2019 Aug;55(8):467.

12. Bartlett K, Kaarid K, Gervais N, Vu N, Sharma S, Patel T, Shea AK. Pregnant canadians' perceptions about the transmission of cannabis in pregnancy and while breastfeeding and the impact of information from health care providers on discontinuation of use. Journal of Obstetrics and Gynaecology Canada. 2020 Nov 1;42(11):1346-50.

13. Liu $X$, Chen $M$, Wang $Y$, Sun L, Zhang J, Shi Y, Wang J, Zhang H, Sun G, Baker PN, Luo X. Prenatal anxiety and obstetric decisions among pregnant women in Wuhan and Chongqing during the COVID-19 outbreak: a cross-sectional study. BJOG: An International Journal of Obstetrics \& Gynaecology. 2020 Sep;127(10):1229-40.

14. Dieterich R, Demirci J. Communication practices of healthcare professionals when caring for overweight/obese pregnant women: a scoping review. Patient Education and Counseling. 2020 Oct 1;103(10):1902-12.

15. Bustamante G, Mantilla B, Cabrera-Barona P, Barragán E, Soria S, Quizhpe E, Aguilar AJ, Trujillo MH, Wang E, Grunauer M. Awareness of obstetric warning signs in Ecuador: a cross-sectional study. Public health. 2019 Jul 1;172:52-60.

16. Goshin LS, Sissoko DG, Neumann G, Sufrin C, Byrnes L. Perinatal nurses' experiences with and knowledge of the care of incarcerated women during pregnancy and the postpartum period. Journal of Obstetric, Gynecologic \& Neonatal Nursing. 2019 Jan 1;48(1):27-36.
17. Wulandaria RD, Laksonob AD. Education as predictor of the knowledge of pregnancy danger signs in Rural Indonesia. Education. 2020;13(1).

18. Egawa M, Hara K, Ikeda M, Kono E, Miyashita S, Miyasaka $\mathrm{N}$, Inaji M, Maehara T, Yoshida M. Role of obstetricians in promoting pregnancy-related knowledge among women with epilepsy in Japan. Epilepsy \& Behavior. 2020 Oct 1;111:107176.

19. Navarro A, Sison JM, Puno R, Quizon T, Manio LJ, Gopez J, Tiongco RE, Bundalian Jr R. Reducing the incidence of pregnancy-related urinary tract infection by improving the knowledge and preventive practices of pregnant women. European Journal of Obstetrics \& Gynecology and Reproductive Biology. 2019 Oct 1;241:88-93.

20. Ceulemans M, Van Calsteren K, Allegaert K, Foulon V. Beliefs about medicines and information needs among pregnant women visiting a tertiary hospital in Belgium. European journal of clinical pharmacology. 2019 Jul;75(7):995-1003.

21. Letose F, Admassu B, Tura G. Birth preparedness, complication readiness and associated factors among pregnant women in Agnuak zone, Southwest Ethiopia: a community based comparative cross-sectional study. BMC pregnancy and childbirth. 2020 Dec;20(1):1-5.

22. Teekhasaenee T, Kaewkiattikun K. Birth preparedness and complication readiness practices among pregnant adolescents in Bangkok, Thailand. Adolescent health, medicine and therapeutics. 2020;11:1. 